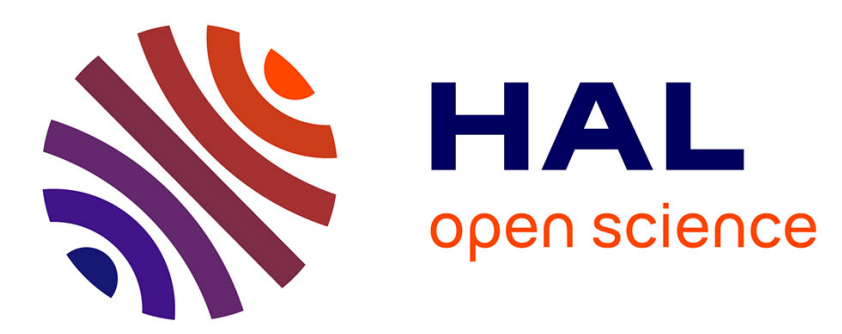

\title{
Generic PLM system for SMEs: Application to an equipment manufacturer
}

Julien Le Duigou, Alain Bernard, Nicolas Perry, Jean-Charles Delplace

\section{To cite this version:}

Julien Le Duigou, Alain Bernard, Nicolas Perry, Jean-Charles Delplace. Generic PLM system for SMEs: Application to an equipment manufacturer. Int. J. of Product Lifecycle Management, 2012, 6 (1), pp.51 - 64. 10.1504/IJPLM.2012.046429 . hal-00951458

\section{HAL Id: hal-00951458 https://hal.science/hal-00951458}

Submitted on 26 Feb 2014

HAL is a multi-disciplinary open access archive for the deposit and dissemination of scientific research documents, whether they are published or not. The documents may come from teaching and research institutions in France or abroad, or from public or private research centers.
L'archive ouverte pluridisciplinaire HAL, est destinée au dépôt et à la diffusion de documents scientifiques de niveau recherche, publiés ou non, émanant des établissements d'enseignement et de recherche français ou étrangers, des laboratoires publics ou privés. 


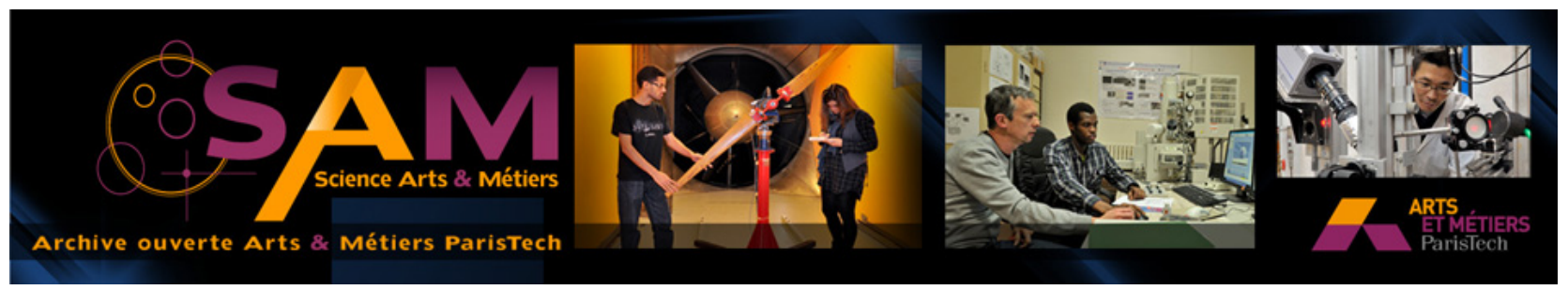

Science Arts \& Métiers (SAM)

is an open access repository that collects the work of Arts et Métiers ParisTech researchers and makes it freely available over the web where possible.

This is an author-deposited version published in: http://sam.ensam.eu

Handle ID: .http://hdl.handle.net/10985/7795

\section{To cite this version :}

Julien LE DUIGOU, Alain BERNARD, Nicolas PERRY, Jean Charles DELPLACE - Generic PLM system for SMEs: Application to an equipment manufacturer - Int. J. of Product Lifecycle Management - Vol. 6, n¹, p.51- 64 - 2012 


\title{
Generic PLM system for SMEs: Application to an equipment manufacturer
}

\author{
J. Le Duigou*, A. Bernard*, N. Perry**, J.C. Delplace ${ }^{\star \star \star}$ \\ *IRCCYN - UMR 6597 \\ **I2M - UMR 5295 \\ *** CETIM
}

\begin{abstract}
For several years, digital engineering has increasingly taken a more important place in the strategic issues of mechanical engineering companies. Our proposition is an approach that enables technical data to be managed and used throughout the product life-cycle. This approach aims to provide assistance for costing, development and industrialization of the product, and for the capitalization, the reuse and the extension of fundamental knowledge. This approach has been experimented within several companies. This paper presents the case in a company environment that designs and produces families of ship equipment parts.
\end{abstract}

Keywords: Product Life cycle Management, Meta Model, Axiomatic Design

\section{Introduction}

In the present industrial context, mechanical engineering industries are facing growing challenges. After having refocused on their primary business in order to increase their production by increasing efficiency, they are now asked to acquire more diversified skills. Market globalisation and an increase in customer demands has forced companies to produce more complex and individualized products in a shorter lead-time. To solve this paradox, companies have adapted by regrouping in order to pool their mutual skills. 'Virtual enterprise' arose for short-term collaborations focused on a specific project, whereas 'extended enterprise' sets up for longer and deeper collaborations between companies (Browne, 1999).

One of the key points of the success of such kind of enterprise structures is the ability to communicate about and around the product. Products generate a large amount of information, so the classical communication systems phone/fax/email used by $90 \%$ of companies are not structured enough to enable efficient cooperation. For many years, software as PLM was developed to pool all this information.

Within this context, Cetim (French industrial technical centre that represents 7000 companies in the field if mechanical engineering industries) launched a survey in 2007 on digital and collaborative engineering for the mechanical engineering companies (Cetim, 2007). This survey showed that only 5\% of SMEs of fewer than 100 people use a PLM system to manage their technical data. Moreover, more than $70 \%$ of these same SMEs consider as important the reuse of knowledge, the sharing of information in the company and with the outside, the security of information access and storage and the follow-up of modifications. These are the exact functionalities offered by the PLM software tools.

\section{Copyright (C) 200x Inderscience Enterprises Ltd.}


Recent surveys evaluate the main difficulties in the implementations of PLM systems in SMEs (El Kadiri, 2009). Combined with previous studies in mechanicals SMEs (Cetim, 2007) (Balocco, 2006), it results that the main difficulties that arise for the implementation of PLM system for SMEs are:

- The gap between the functionalities proposed by the actual software and the needs of some kind of enterprise, especially the raw part makers.

- The difficulty of modelling business processes and data models. The modelling skills are not sufficiently present in SMEs.

- The lack of interoperability between PLM and CAD, ERP and PLM of partner companies.

Section 2 focuses on the scientific studies that enable to establish the starting point of the approach. In section 3, the working method is presented. In section 4, the industrial case study, an equipment manufacturer, will be described.

\section{PLM: from concept to data model}

For many years, the software providers have extolled the merits of PLM and the return on investment of that information systems. But PLM is first of all an enterprise strategy (Stark, 2004). It involves managing all the data concerning a product, throughout its lifecycle, and all the internal and external actors involved in the development of this product. An acceptable definition of PLM is: "A strategic business approach that applies a consistent set of business solutions in support of the collaborative creation, management, dissemination and use of product definition information across the extended enterprise from concept to end of life - integrating people, processes, business system, and information" (CIMData, 2003).

Nevertheless, in an extended enterprise context, it is necessary for these different models being able to interoperate together. Different possibilities exist as the use of standardized models that enable sharing and communication between companies. Much work was done in different sectors to increase the interoperability of data models with the standards (Subrahmanian et al., 2005), using mainly the STEP (STandards for the Exchange of Product model data) ISO norm (ISO 10303), (Chambolle, 1999; El Khalkhali et al., 2002). The AP214 (ISO 10303-214, 1998) is widely used in the automobile sector, whereas the AP239 (ISO 10303-239, 2005; Pratt, 2005) focuses more on the aeronautic sector. Those models are not fully interoperable, despite having common integrated resources. The main reason is that the objects and the attributes are different depending on the sector of application. Hence, the creation of PDM Schema (PDM Schema, 2001) that tries to unify the different information models of STEP APs using their common objects.

Much work has been done in this field, especially in the aeronautic and automobile sectors in order to propose technical data management methods (Bacha, 2002; McMahon, 2005; Nguyen Van, 2006), but also in smaller companies, such as foundries (Delplace, 2004). Numerous projects, like Promise (Promise, 2007) or Bridge (Bridge, 2009), propose methods and models exploiting the whole product lifecycle information in so called closed-loop PLM. It includes the phases of use, maintenance and end of life in the collection of data. The produced data for the whole lifecycle are now available. For example RFIDs, embedded systems and wireless communication allows collecting information during the use or maintenance phases. Those projects lead to describe data 
models adapted to the encapsulation of knowledge and data from the product all over the lifecycle. Those models and ontologies, like in (Matsokis, 2010), include the product definition "as designed" but also "as built" and "as maintained". The goal of those models, like in (Cassina, 2009) is to improve the interaction between the enterprise and the customer.

These models are more adapted to some kind of companies, especially in a business to consumer (B to C) economic model, than to the mechanical SMEs present in our work, like equipment part manufacturers. Indeed the closed-loop PLM is more valuable when the interaction is direct between the company and the end user of the product. In the case of a second or third rank supplier, this interaction seems to be more difficult. Moreover those methods and data models are very complex and require investment and skills that are not yet available in all mechanical SMEs.

The next section will present our research approach to create a modelling framework based on a bottom-up method to obtain a generic model for SMEs.

\section{Research approach}

The proposed method specifies PLM system to be implemented in mechanical SMEs. It is a four steps method that gives functional needs of the company, processes to implement to solve these needs and business objects used in these processes. A final step automates some processes to validate the previous models.

- Identify needs: the analysis phase is done by interviewing and observing the experts. The implicit and explicit needs about PLM have to be identified. The explicit needs could be identified by the interviews but the implicit needs need the observation or the realization of the task by an external person, the modeler. The observation of the experts show how the technical data are use in the company, their purposes, their processes... the realization of some tasks of the experts permits to the modeler to fill the different gaps in the processes of creation and transformation of the technical data. The needs could be express through a SysML requirement diagram or a less formal language to facilitate the exchange with the experts, like a mind map.

- Modeling the processes to realize the identified needs: the goal of this step is to formalize the "to be" business processes that will respond to the identified needs. The language to model the processes could be SADT, IDEF0, BPMN or an UML sequential diagram. In this work, the selected language is SADT because it is the only one that the experts already know in the mechanical SMEs of our study.

- Extraction of the business objects: the extraction of the business object allows creating the right data model that will be integrated to the PLM system. The objects are extracted from the "to be" processes. The objects are the inputs and outputs of those processes. To represent the data model, the UML class diagram is chosen. This language does not have to be understood only by the experts, but also by the database engineers for the implementation of the PLM system. UML is one of the most known languages in both domains.

- Automation: Before implementing the data model, a automation is done to validate the good understanding of the requirements and their resolution through the "to be" processes supported by the data model. A demonstrator is created to respond to requirements automating a process. The confrontation of this demonstrator with the appropriated experts allows validating the three first stages. 
The next section is a case study at an equipment manufacturer.

\section{A equipment manufacturer: PSL Concept}

This case study must enable us to put into practice methods of technical data structuring and management, adapted to this specific company. In order to do this, the method begins by analysing the needs of the company in terms of PLM. Then it proposes an approach to improve on the initial situation. Finally, it validates the models by automating the analysed process on a product family.

\subsection{Description of the company and needs analysis}

PSL Concept produces and sells equipment for ships. Among these products, there are reserve rudders, pulleys and tackles, sheaves, jam cleats and various accessories.

This company organizes the main part of their products into families. In fact, as many system integrators, their products starts from standard products, on which options and modifications are added to meet customer needs. The chosen family is a major and wellknown family of products for the company: the pulleys.

A standard pulley (Figure 1) is composed of two flanges (1), of one or more sheaves (2), of fastening and of different accessories as for example a jam cleat. To translate the movement, the fag end (a sailboat string) moves onto the sheave's groove. The flanges have many options such as adding guides (4) to maintain the contact between fag end and sheave in special use conditions or beckets (5) and different kinds of openings (3) to fix the pulley. Various processes are used to produce the parts, the composite carbon blocks are polymerised, then cut by milling, and are finally manually assembled with the other parts.

Figure 1 Description of a pulley.

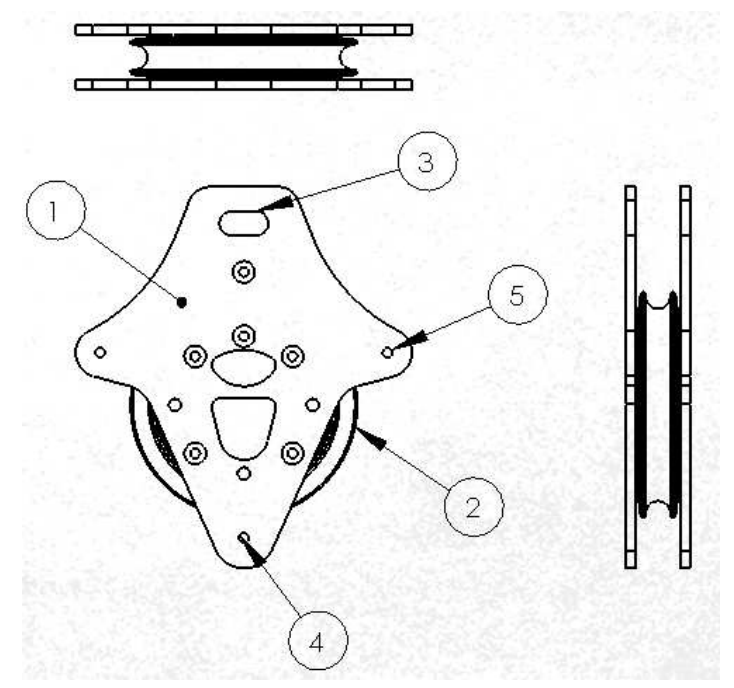

After an audit of the company, the main needs in terms of PLM are as follows: 
- Knowledge capitalisation: an improvement of design, resulting from customer feedback, a set of tests or the optimization of the designer, are not reproduced on the other products of the family without the involvement of the designer on each product. This process is lengthy and is a source of error.

- Bill of Material (BoM) management: the BoM are manually edited and have to be updated if a modification appears on the product design.

- Reference management: the product references are hard to manage efficiently due to large number of referenced products (1200 only for pulleys).

- Quote: no detailed process is available at the early design and quotation phases. That makes difficult to know, for example, the quantities of raw materials and the manufacturing time before the detailed design of the product.

- Archive management: when a client comes back with a product, it is not always easy to find the original drawings of the product that has exactly been sold with the references of the different parts.

\subsection{Business processes modelling}

The families in PSL Concept could be organized by main functions of the products. It seems that an organisation of technical data by function could be the most efficient way of being able to link the design parameters and the functions of the product. With this organisation, the technical data are globally managed depending on the functions of the family.

Suh (Suh, 1990) proposes the Axiomatic Design that links the functional parameters to the design parameters. He divides the design into four domains (customer, functional, physical, process). Each domain contains specific design objects (customer needs (CNs), functional requirements (FRs), design parameters (DPs) and process variables (PVs)).

The functional requirements defines the minimum data that fully complete the customer needs. The design process moves on by breaking down the hierarchical upper level and zigzagging between functional, physical and process domains. Axioms guide the designers within the choices. Two design axioms have been defined as follows:

First axiom - independency axiom: maintain the independence of functional requirements.

Second axiom - information axiom: minimize the information content (of the design).

Design matrix representing the links between FRs and DPs enable the design to be visualized and optimized by applying axioms.

The design matrixes show the relation between the FRs and the DPs at a given level of the design hierarchy. There are three natures for the design matrix: it can be a triangular matrix, known as decoupled matrix, a diagonal matrix, known as uncoupled matrix or any other kind of matrix, known as coupled matrix (Figure 2).

Figure 2 Design matrix a) coupled, b) uncoupled, c) decoupled

\begin{tabular}{|l|l|l|l|l|l|l||l|l|l|}
\hline & DP1 & DP2 & & DP1 & DP2 & & DP1 & DP2 \\
\hline FR1 & $\times$ & $\times$ & FR1 & $\times$ & $\bigcirc$ & FR1 & $\times$ & $\bigcirc$ \\
\hline FR2 & $\times$ & $\times$ & FR2 & $\times$ & $\times$ & FR2 & $\bigcirc$ & $\times$ \\
\hline
\end{tabular}

(a)

(b)

(c) 
This principle is adapted and declined into the technical data structuring and management of a products family. The different functions of the family are broken down, and create a set of functional dimensioning parameters for the products in order to link those parameters to the different functions (Figure 3).

Figure 3 Decomposition of a product family through Suh domains

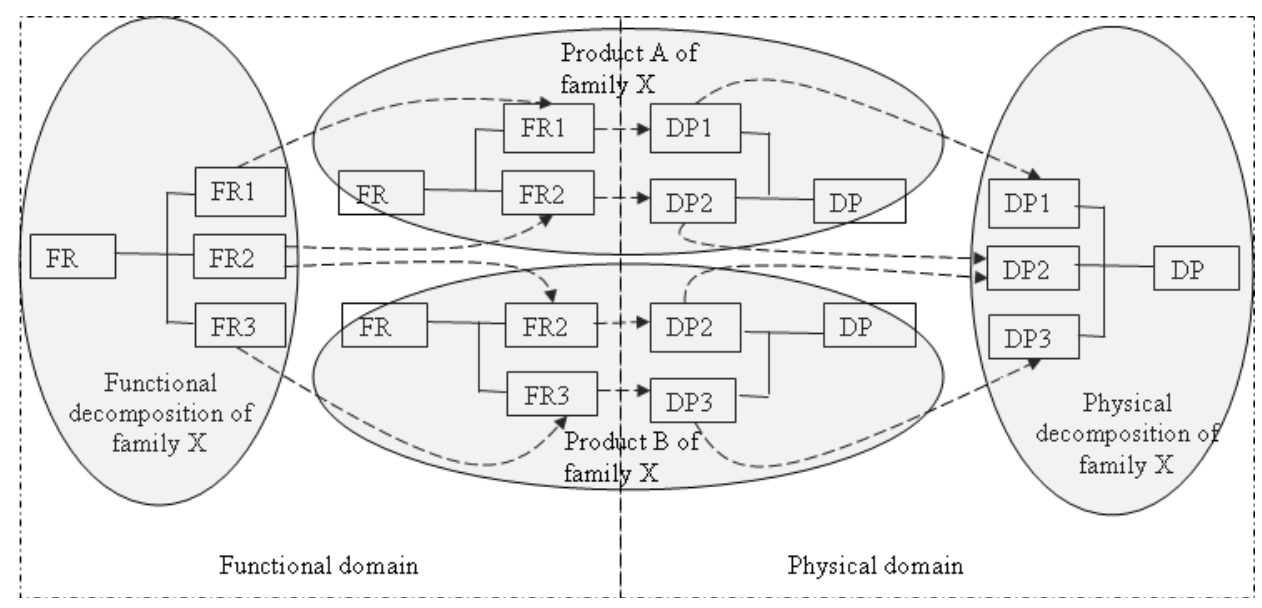

To create the link between the functional parameters and the design parameters, the design matrix of the product are needed. The equations are solved to link the FRs to the DPs when the matrix is decoupled or uncoupled ("good design" in the axiomatic design theory).

Thus, if the customer does not require a function, and if this function is only linked to a single sub-product, then this sub-product will not be present in the final product. The word sub-product is for a part in an assembly and for a part of a part. Moreover, the modification of a functional parameter leads to the modification of the design parameters that are linked to it.

On this basis, several functionalities are developed to meet the needs in terms of PLM for this company.

- Knowledge capitalisation: when a modification of the design is made, this modification is implemented on all the products of the family that use the function concerned by the modification. There is no longer information loss when a product is improved because if the function or the definition of the design parameter is modified, all the products of the family will be automatically modified and so have the benefit of the improvement.

- Reference management: in order not to have to open a large number of references without producing the referenced product, a system of referencing based on the functions of the product family is introduced. This system enables that a new product (an unseen combination of functions) automatically obtains a reference link to the specified functions, without having to open all the possible references beforehand.

- Quote: The price of a product is linked to the functions of this product. So ascertaining empirically the relation between the price and each function, a price for a product is obtained from its functional definition. 
- Archive management: by registering the modification dates of functional parameters and the former values of these parameters, the exact CAD of a past product can be found, by using the parameters at the product sale date.

\subsection{Business objects extraction}

Analyzing inputs and outputs of the processes, the following documents have been extracted: functional requirements, assembly CAD files, component CAD files, 2D drawings, BoM... To create the generic model, the following method is applied:

- Select the documents that deal with PLM.

- Group documents by theme and identify the concepts and the objects representing each group. This phase is performed by a cognitive analysis of the modeller based on a semantic analysis.

- Detail the objects. This step is performed by an extraction of the intersection of attributes and methods.

- Link the different objects. This is done by identifying the various links between documents of different groups.

This process is applied to the documents extract from the analysed processes. The result is the following data model (Figure 4).

Figure 4 PSL Concept data model.

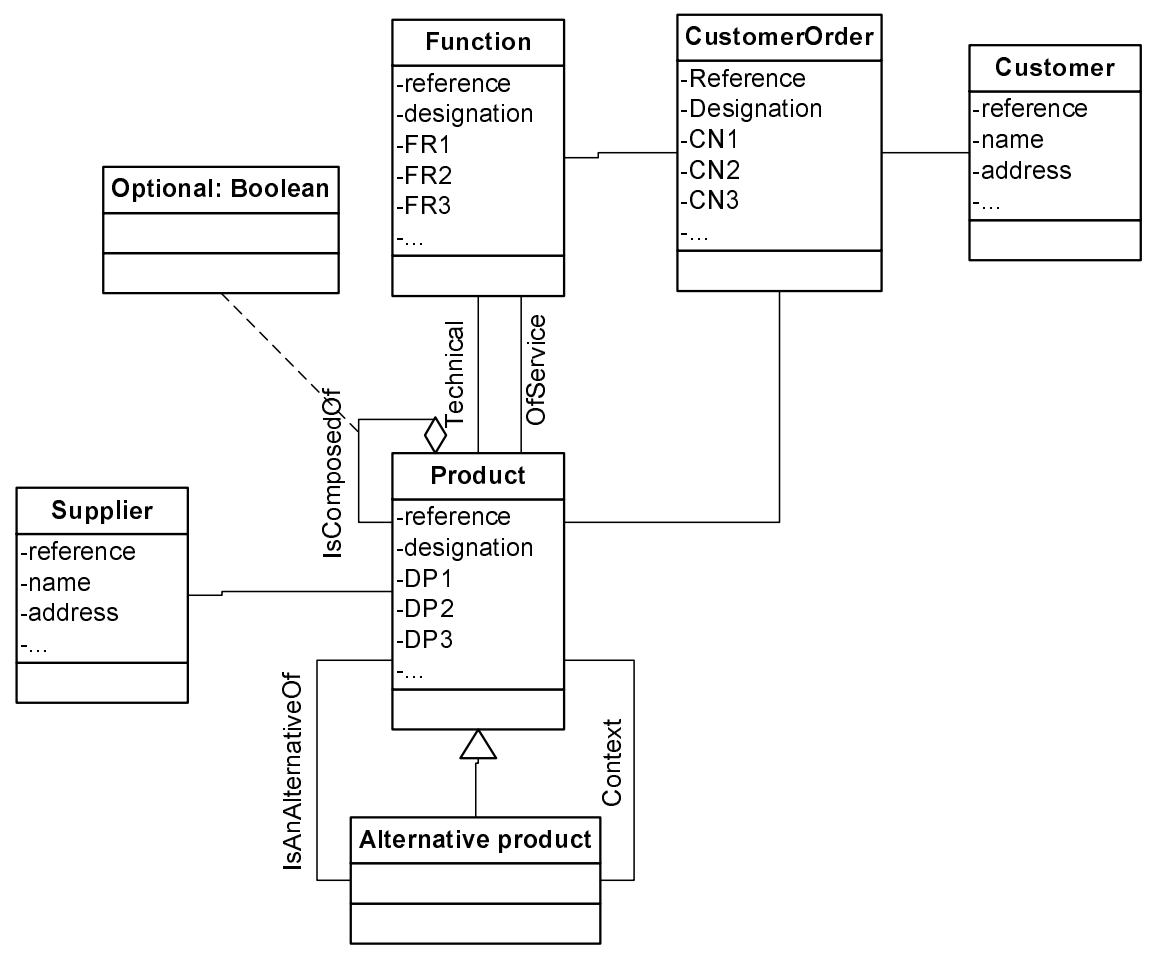

The customer sends an order. The order describes the different customer needs. The order is linked to functions. The function is connected to the product, as a technical 
function or a service function, via the selected link. The product is composed of products, which may be optional. A product (component) can have alternative products (components) in an assembly context. When it is a bought product, it is connected to a supplier. Finally, the product is linked to the order.

\subsection{Automation of the approach}

A software program, made using Visual Basic and Solidworks API (Application Programming Interfaces), was implemented to automatically construct the CAD file of a pulley from the functional requirements.

To create this program the functionalities of a pulley is broken down (Figure 5) into a list of functions and functional parameters. Then options are defined and linked to those functions (Table 1) to obtain discreet values for the functional parameters. A functional dimensioning of the different parts of the pulley was implemented in the CAD model. The parameters were grouped according to the different functions of the pulley aimed to link the functions of the pulley and the parameters of the CAD model (Table 2). The values of those parameters are calculated according to the specific craft rules defined by the firm and the values of the functional parameters. Other dimensions are also needed to obtain the full CAD model, but they are a pro rata of the previous parameters of Table 2. As a result an only CAD file represents the whole pulley family. All the parameters and their definitions are temporarily stored in a spreadsheet. They will be stored in the PLM database.

Figure 5 Partial functional decomposition of a pulley.

\begin{tabular}{|c|c|c|}
\hline & $\begin{array}{l}\text { F1 : hold on the move ment } \\
\text { FR1 : fag end diameter } \\
\text { FR2 : number of sheaves } \\
\text { FR } 3 \text { : type of sheave }\end{array}$ & \\
\hline & & \\
\hline $\begin{array}{l}\text { F11: keep the contact } \\
\text { between the sheave } \\
\text { and the fag end } \\
\text { FR11: angle of } \\
\text { traction }\end{array}$ & $\begin{array}{l}\text { F12: enable to fix } \\
\text { the pulley } \\
\text { FR12: type of } \\
\text { opening }\end{array}$ & $\begin{array}{l}\text { F13: hold on against } \\
\text { external effects } \\
\text { FR13: extreme } \\
\text { constraint/ normal } \\
\text { constraint }\end{array}$ \\
\hline
\end{tabular}

Table 1 Design parameters and associate options

\begin{tabular}{lll}
\hline \multirow{2}{*}{ Functions } & Options & Choice \\
\hline General operations & Fag end diameter & $6 / 8 / 10 / 12$ \\
\cline { 2 - 3 } & Type of sheave & Big/ Small/ Fiddle \\
\cline { 2 - 3 } & Number of sheave & Simple/ Double/ Triple \\
\hline Enable to fix the pulley & Type of opening & Shackle/ swivel/ shafing/ mat/ clinch \\
\hline Keep the contact between the fag end and the sheave & Becket & Yes/No \\
\cline { 2 - 3 } & Guide & Yes/No \\
\hline
\end{tabular}


Table 2 Link between functions and options

\begin{tabular}{|c|c|c|c|}
\hline Parameter & Value & Unit & Associate function \\
\hline Plate length & 300 & $\mathrm{~mm}$ & \multirow[t]{3}{*}{ Blank parameters } \\
\hline Plate breadth & 300 & $\mathrm{~mm}$ & \\
\hline Plate thickness & 3.5 & $\mathrm{~mm}$ & \\
\hline Sheave diameter & 84 & $\mathrm{~mm}$ & \multirow[t]{2}{*}{ Fag end parameters } \\
\hline Number of hole sheave & 8 & Unit & \\
\hline Becket radius1 & 10 & $\mathrm{~mm}$ & \multirow[t]{3}{*}{ Becket parameters } \\
\hline Becket radius2 & 11 & $\mathrm{~mm}$ & \\
\hline Becket fillet & 12 & $\mathrm{~mm}$ & \\
\hline Guide angle & 70 & $\circ$ & \multirow[t]{3}{*}{ Guide parameters } \\
\hline Guide distance & 8 & $\mathrm{~mm}$ & \\
\hline Guide fillet & 8 & $\mathrm{~mm}$ & \\
\hline Swivel distance & 5.45 & $\mathrm{~mm}$ & \multirow{8}{*}{$\begin{array}{l}\text { Opening of the } \\
\text { flange }\end{array}$} \\
\hline Shackle distance & 4 & $\mathrm{~mm}$ & \\
\hline Clinch distance & 8 & $\mathrm{~mm}$ & \\
\hline Clinch length & 16 & $\mathrm{~mm}$ & \\
\hline Clinch breadth & 8 & $\mathrm{~mm}$ & \\
\hline Shafing mat distance & 8.3 & $\mathrm{~mm}$ & \\
\hline Shafing mat length & 8 & $\mathrm{~mm}$ & \\
\hline Shafing mat breadth & 16 & $\mathrm{~mm}$ & \\
\hline Evacuation radius 1 & 12 & $\mathrm{~mm}$ & \multirow{4}{*}{$\begin{array}{l}\text { Evacuation } \\
\text { parameters }\end{array}$} \\
\hline Evacuation radius2 & 8 & $\mathrm{~mm}$ & \\
\hline Evacuation fillet1 & 3 & $\mathrm{~mm}$ & \\
\hline Evacuation fillet2 & 3 & $\mathrm{~mm}$ & \\
\hline Screw diameter & 3.2 & $\mathrm{~mm}$ & \multirow{2}{*}{$\begin{array}{l}\text { Fastening } \\
\text { parameters }\end{array}$} \\
\hline Washer diameter & 7.1 & $\mathrm{~mm}$ & \\
\hline
\end{tabular}

An example for a specific function is detailed: the function "to keep the contact between the fag end and the sheave" (Figure 6) when the parameter "angle of traction" is greater than $90^{\circ}$. If the maximum angle of traction is greater than $90^{\circ}$, guides are added to the flanges with a screw between the two flanges (reference 4 in Figure 1). The fag end passes between the sheave and the screw and is forced to stay in contact with the sheave. On the CAD model, the feature "guide extrusion" passes automatically from a suppressed state to a resolved state. The construction parameters of the guide are then downloaded and filled in, according to the function requirements (Figure 6 and Table 3). 
Figure 6 Sketch of the guide on the flange.

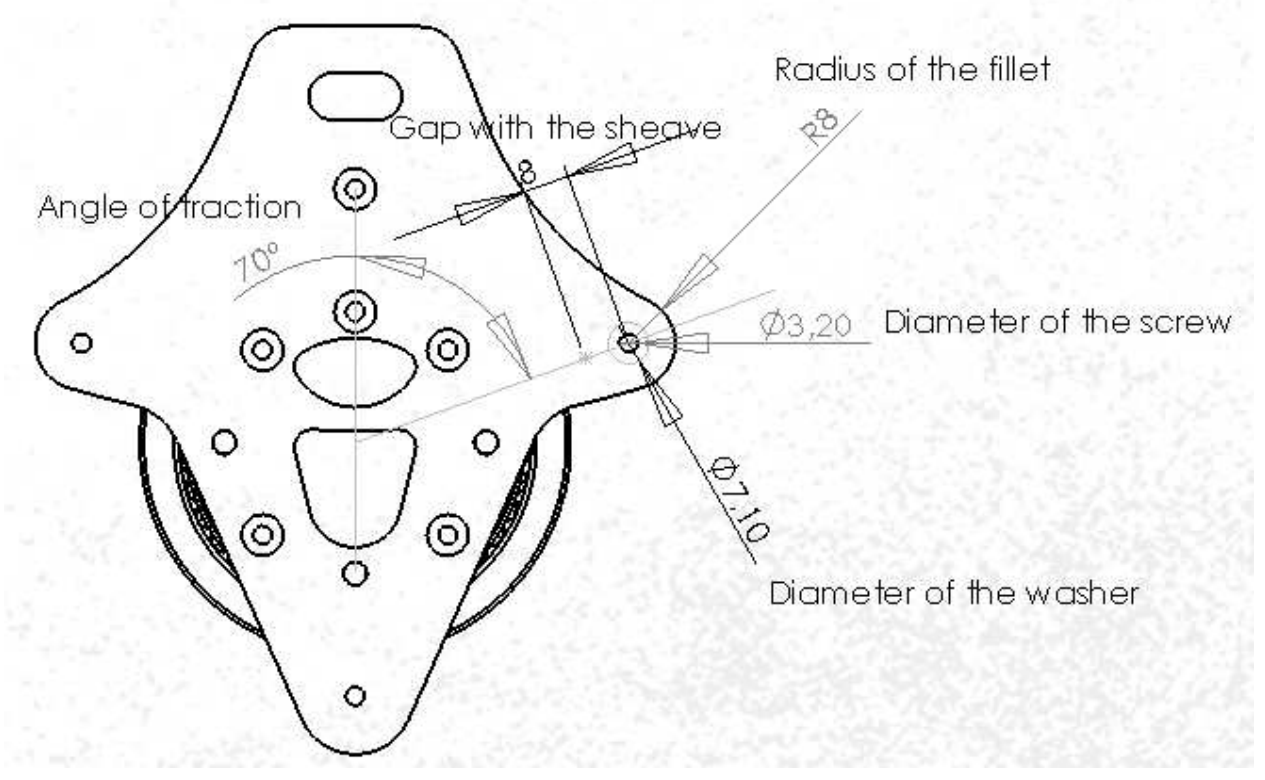

Table 3 Design parameters of the guide.

\begin{tabular}{llllll}
\hline Guide parameters & $\begin{array}{l}\text { Angle of the } \\
\text { guide }\end{array}$ & $\begin{array}{l}\text { Gap with the } \\
\text { sheave }\end{array}$ & $\begin{array}{l}\text { Diameter of } \\
\text { the screw }\end{array}$ & $\begin{array}{l}\text { Diameter of } \\
\text { the washer }\end{array}$ & $\begin{array}{l}\text { Radius of the } \\
\text { fillet }\end{array}$ \\
\hline $\begin{array}{l}\text { Definition in } \\
\text { function of the FRs }\end{array}$ & $\begin{array}{llll}180^{\circ}-\text { angle of } \\
\text { traction }+10^{\circ}\end{array}$ & $\begin{array}{l}\text { Fag end } \\
\text { diameter }+ \\
4 \mathrm{~mm}\end{array}$ & Constant & Constant & $\begin{array}{l}\text { Fag end } \\
\text { diameter }+ \\
4 \mathrm{~mm}\end{array}$ \\
\hline
\end{tabular}

When one of guide parameters is changed, all the pulleys that have an "angle of traction" functional requirement greater than $90^{\circ}$ will be modified. No more need to change the value of the parameters, because the change affects directly their definition. If the fag end is often jammed between the screw of the guide and the sheave (cause by an accumulation of impurities), then the definition of the parameter "gap with the sheave" is changed from "fag end diameter $+4 \mathrm{~mm}$ " to "fag end diameter $+5 \mathrm{~mm}$ ". Then all the new pulleys with a maximum angle of traction greater than $90^{\circ}$ will have $1 \mathrm{~mm}$ more in the gap between the screw and the sheave, so the impurities will no longer jam the end fag.

\subsection{Conclusions on the case study}

First, the software carries out a needs analysis. Then it produces the CAD model for the specific pulley, shows the quote, opens a reference if necessary and creates the layouts and the BoM. The design time for a new pulley has gone from hours to minutes. 
Moreover there is now a single $\mathrm{CAD}$ file to manage, with an associated table of parameter definitions for the 1200 pulley references. With the record of modifications of the parameter definitions and the functional requirements of each sold product, an old version of a pulley is recreated directly from this CAD file.

An approach is proposed to meet the specific PLM needs of this company. The implementation of the software based on this approach and the results obtained prove that the approach is in phase with the needs of this kind of company. Nevertheless, a family of well-known products was chosen. What about the feasibility of this approach if a new range of products is chosen. Many parameter definitions were obtained with an empirical value, and it could be difficult to assume those coefficients for a new product range.

\section{Conclusions and prospects}

An approach to meet PLM needs of an equipment manufacturer is proposed and implemented. The results obtained confirm that this solution meets the needs in terms of PLM of this type of company. But, in an extended enterprise, the approach could not be limited to one type of company and on one functionality (here design) in the network. It must be possible to link integrators, detail parts producers and mould makers or machine tool producers in order to bring a modern industrial project to fruition. That is why our other portfolio of industrial cases is made of different kind of enterprises. For example the other test cases integrate an elementary part producer and a machine tool producer. That will enable us to underline the specific problems of the other type of companies and of the other life-cycle steps.

In parallel the structure of a meta-model of the PLM for SMEs in Mechanical Manufacturing is built. All the elementary cases study brings together the basics bricks of a more complete software and information system solution. As a conclusion, the case study allow us to built from the experiment a information system to fit with the SMEs requirements in term of PLM. Each case gives us also the possibility to apply and improve the predefine methodology.

\section{Acknowledgement}

We would like to thank PSL Concept for allowing us to carry out our study in and for their technical support.

\section{References}

Bacha, R. (2002) 'De la gestion des données techniques pour l'ingénierie de production. Référentiel du domaine et cadre méthodologique pour l'ingénierie des systèmes d'information techniques en entreprise', Thèse de doctorat, Ecole Centrale Paris.

Balocco R., Mainetti S., Rangone A., 2006. Innovare e competere con le ICT - Il ruolo delle tecnologie dell'informazione e della comunicazione nella crescita delle PMI, IlSole24ore, Milano.

BRIDGE Final Report: http://www.bridge-project.eu/data/File/BRIDGE_Final_report.pdf, 2009.

Browne J., Zhang J. (1999) 'Extended and virtual enterprises - similarities and differences', International Journal of Agile Management Systems, vol. 1, pp. 30-36. 
Generic PLM system for SMEs: Application to an equipment manufacturer

Cassina, J.; Cannata, A.; Taisch, M.: Development of an Extended Product Lifecycle Management through Service Oriented Architecture, Proceedings of CIRP IPS2 Conference, 2009.

Cetim (2007) 'Enquête de besoin sur le travail collaboratif', Document interne.

Chambolle, S. (1999) 'Un modèle produit piloté par les processus d'élaboration: Application au secteur automobile dans l'environnement STEP', Thèse de doctorat, Ecole Centrale Paris.

CIMdata Inc. (2003) 'Product Lifecycle Management "Empowering the future of business"'.

Delplace, J.C. (2004) 'L'Ingénierie numérique pour l'amélioration des processus décisionnels et opérationnels en fonderie', Thèse de Doctorat, École Centrale de Nantes.

El Kadiri, S., Pernelle, P., Delattre, M., Bouras, A., 2009. Current situation of PLM systems in SME/SMI: Survey's results and analysis. Proceedings of $6^{\text {th }}$ International Conference on Product Lifecycle Management.

El Khalkhali, I., Ghodous, P., Martinez, M., Fravel, J. (2002) 'An information infrastructure to share product models using STEP standard', $9^{\text {th }}$ IPSE international conference on concurrent engineering: research and applications, Cranfield University, $27^{\text {th }}-31^{\text {st }}$ July 2002.

ISO 10303-214 (1998) 'Industrial Automation Systems and Integration - Product Data Representation and Exchange - Part 214: Application Protocol: Core Data for Automotive Mechanical Design Processes'. ISO - International Organization for Standardization.

ISO 10303-239 (2005) 'Industrial Automation Systems and Integration - Product Data Representation and Exchange - Part 239: Application Protocol: Product Life Cycle Support'. ISO - International Organization for Standardization.

Matsokis A.; Kiritsis D.: An Ontology-based Approach for Product Lifecycle Management, Computers in Industry, 61(8), 2010, 787-797

McMahon, C., Giess, M., Culley, S., (2005), 'Information management for through life product support: the curation of digital engineering data', International Journal of Product Lifecycle Management 2005 - Vol. 1, No.1 pp. 26 - 42

Nguyen Van, T. (2006) 'System engineering for collaborative data management systems: Application to design/simulation loops', $\mathrm{PhD}$ thesis, Ecole Centrale Paris.

PDM Schema (2001) ,'PDM Schema v1.2': http://www.pdm-if.org/pdm_schema/index.html

Pratt, M.J. (2005),' ISO 10303, the STEP standard for product data exchange, and its PLM capabilities', International Journal of Product Lifecycle Management 2005 - Vol. 1, No.1 pp. 86 - 94.

PROMISE Research Deliverable 9.6: http://www.promise.no/downloadfile.php?i=877a9ba7a98f75b90a9d49f53f15a858, 2007.

Stark, J. (2004), Product Lifecycle Management:

Subrahmanian, E., Rachuri, S., Fenves,S.J., Foufou, S., Sriram, R.D. (2005) 'Product lifecycle management support: a challenge in supporting product design and manufacturing in a networked economy', International Journal of Product Lifecycle Management 2005 - Vol. 1, No.1 pp. 4 - 25

Suh, N.P. (1990) 'The Principle of Design', Oxford University Press. 